\title{
KOPEC REVISITED-NEUROENDOCRINE REGULATION OF METAMORPHOSIS IN THE GYPSY MOTH (LYMANTRIA DISPAR): DEVELOPMENT OF A LARVAL IN VIVO ASSAY FOR PROTHORACICOTROPIC HORMONE
}

\author{
Belgaum S. Thyagaraja, ${ }^{1,2}$ Thomas J. Kelly, ${ }^{1, *}$ Edward P. Masler, ${ }^{1}$ Dale B. Gelman, ${ }^{1}$ \\ ROBERT A. BELL, ${ }^{1}$ and RICHARD B. IMBERSKI ${ }^{2}$ \\ ${ }^{1}$ Insect Neurobiology and Hormone Laboratory, USDA, ARS, Beltsville, MD 20705 and \\ ${ }^{2}$ Department of Zoology, University of Maryland, College Park, MD 20742, U.S.A.
}

(Received 14 April 1992)

\begin{abstract}
The role of the brain as a neuroendocrine regulator of metamorphosis in the gypsy moth, Lymantria dispar L. was originally demonstrated by Kopec more than 70 years ago. We have reexamined this role by determining haemolymph ecdysteroid titres, activity and responsiveness of the prothoracic glands, and growth of female last (i.e. fifth)-instar larvae in relation to secretion of the brain prothoracicotropic hormonc (PTTH), the factor known to trigger moulting and metamorphosis in insects. The head critical period for secretion of PTTH in Lymantria reared at $25^{\circ} \mathrm{C}$ in a $16 \mathrm{~h}$ light- $8 \mathrm{~h}$ dark cycle was shown by neck ligation to occur on day 7-8 of the fifth instar. The critical period occurred shortly after a small peak of haemolymph ecdysteroid that reached $600 \mathrm{pg} 20$-hydroxyecdysone equivalents $/ \mu 1$, as determined by radioimmunoassay. Feeding was completed by day 7 , thus neck ligation did not affect nutrient intake. Animals starved from day 5 onward completed pupation at the same time as non-starved controls and showed normal increases in haemolymph ecdysteroid titres. Animals neck-ligated on day 7 and injected 5 days later with extracts of brain, retrocerebral complex, or brain tissues containing lateral or median neurosecretory cells were stimulated to pupate within 5 days, and brain-extract-injected animals showed an increase in haemolymph ecdysteroid titre of over $4000 \mathrm{pg} / \mu \mathrm{l}$. Animals neck-ligated earlier had lower haemolymph ecdysteroid titres than day 7 , neck-ligated larvae and their prothoracic glands showed lower activity in vitro. Using the in vivo assay, PTTH activity was detected in pre-hatch eggs and in brains taken from day-5 last-instar larvae, day-1 pupae and day-1 adults. The assay appears specific to tissues from the brain and retrocerebral complex, since no activity was found with extracts of the subesophageal ganglion, fat body or muscle.
\end{abstract}

Key Word Index: Moulting; pupation; ecdysteroids; debraining; starvation; neck-ligation

\section{INTRODUCTION}

In the northeastern United States and southeastern Canada the gypsy moth, Lymantria dispar, defoliates millions of acres of North American hardwood forests annually, and its range is expanding to the South and West. Current control methods have not stopped the spread of this pest (Twardus, 1991), and further knowledge of its fundamental biology is necessary to develop new control methods (Kelly, 1992). Studies on the reproduction and developmental

*To whom all correspondence should be addressed. activity of this insect, first reported by Kopec (1917, 1922), led to the concept of a neuroendocrine system in animals. Subsequent studies with other insect species resulted in the discovery of extremely potent brain hormones that were secreted from storage and release sites in the head during critical periods of insect development (Wigglesworth, 1934, 1940) and to the formulation of a classical theory of action of the cerebral neuropeptide, prothoracicotropic hormone, PTTH (Williams, 1947, 1952). PTTH stimulates the prothoracic glands to produce steroid hormones, ecdysteroids, which control insect growth and development (Bollenbacher and Granger, 1985; Smith, 1985; 
Wigglesworth, 1985). Since Kopec's initial discovery, several other workers have demonstrated through neck ligation or brain removal the importance of a head factor in initiating moulting/metamorphosis in lepidopterous insects (see reviews: Bollenbacher and Granger, 1985; Smith, 1985; Wigglesworth, 1985). These studies led to the development of both larval and pupal lepidopteran bioassays for PTTH activity (Williams, 1947, 1952; Kobayashi, 1955; Gibbs and Riddiford, 1977; Mala et al., 1977; Ishizaki et al., 1983b; Suzuki and Ishizaki, 1986; Muszynska-Pytel, 1987). Such in vivo bioassays are essential for demonstrating the activity and authenticity of isolated neurohormones. Furthermore, species-specific assays may be necessary for the purification of PTTHs from a given species since cross-specific assays can be unreliable. This was demonstrated by Ishizaki et al. (1983a) who reported that small PTTH (i.e. bombyxin) from $B$. mori was active in Samia cynthia ricini pupae but inactive in $B$. mori pupae. To deter- mine the feasibility of developing a larval in vivo assay for Lymantria, the role of the brain in metamorphosis was re-examined through neck ligation, decapitation and debraining of fifth-instar (last-stage) larvae. Preliminary observations on development of this assay in Lymantria were published previously (Thyagaraja et al., 1990b). We include here an in-depth description on the development and utilization of a gypsy moth PTTH in vivo assay.

\section{MATERIALS AND METHODS}

Insect rearing, staging and moulting characterization

New Jersey strain gypsy moths, $L$. dispar, having five larval instars, were obtaincd from cggs raiscd in-house since 1987 and reared on high wheat germ diet (Bell et al., 1981) at $25^{\circ} \mathrm{C}, 50-60 \%$ r.h., under a $16 \mathrm{~h}$ light $-8 \mathrm{~h}$ dark cycle. Larvae were staged from the fourth instar. The larger females were segregated from the males and placed in $180 \mathrm{ml}$ plastic cups with

Table 1. Developmental behaviour during the third day of the fourth instar

\begin{tabular}{|c|c|c|c|c|}
\hline Stage & Time & $\begin{array}{l}\text { Weight (g) } \\
(\text { mean } \pm \text { SE) }\end{array}$ & Moulting characteristics & Dorsal head markings \\
\hline I & $\begin{array}{l}\text { 12:00 p.m. } \\
\text { (12) }\end{array}$ & $0.682 \pm 0.009$ & $\begin{array}{l}\text { Bulging of head capsule with a slight } \\
\text { slippage between head and prothorax }\end{array}$ & \\
\hline II & $\begin{array}{l}\text { 2:00 p.m. } \\
\quad(12)\end{array}$ & $0.723 \pm 0.010$ & $\begin{array}{l}\text { Advanced head slippage with a "V" } \\
\text { shape on neck membraneous cuticle. } \\
\text { "Green-neck" stage }\end{array}$ & \\
\hline III & $\begin{array}{c}\text { 4:00 p.m. } \\
\text { (8) }\end{array}$ & $0.757 \pm 0.014$ & $\begin{array}{l}\text { Appearance of two bars on new head } \\
\text { capsule beneath neck membraneous } \\
\text { cuticle }\end{array}$ & \\
\hline IV & $\begin{array}{l}\text { 1:00 a.m. } \\
(8)\end{array}$ & $0.688 \pm 0.015$ & $\begin{array}{l}\text { Two bars merged together to form a } \\
\text { thick median band. Neck region } \\
\text { becomes brown. "Brown-neck" stage }\end{array}$ & \\
\hline $\mathbf{V}$ & $\begin{array}{l}\text { 4:00 p.m. } \\
\text { (8) }\end{array}$ & $0.650 \pm 0.015$ & $\begin{array}{l}\text { Advanced head slippage and shedding } \\
\text { of old head capsule }\end{array}$ & \\
\hline
\end{tabular}

A total 27-33 h was required to complete the fourth moult for Gate II larvae. The number in the parentheses denotes the number of groups maintained for the observation $(N=10$ larvae/group). Appearance of dorsal head markings at each stage are indicated by an arrow. 

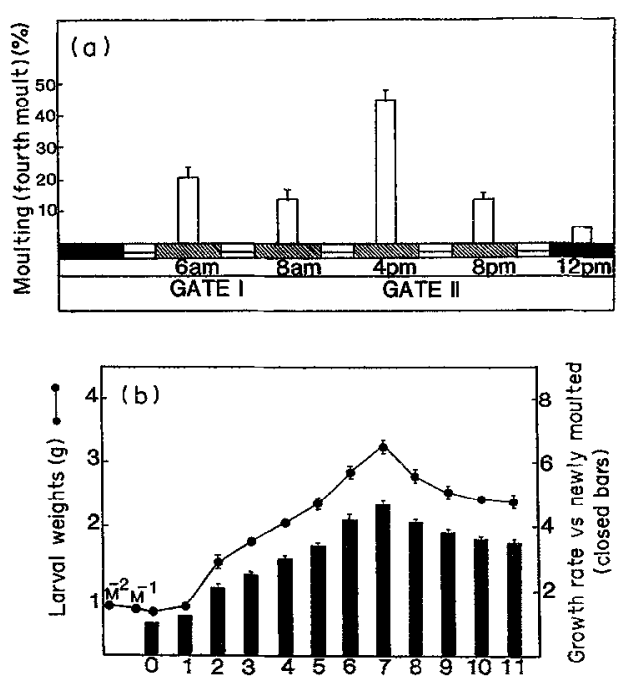

Days of fifth larval instar

Fig. 1. Time of ecdysis, larval weight gain and growth. (a) Female larvae were separated after the third moult (i.e. fourth instar) into groups of 5-7 larvae per cup as described in the Materials and Methods. The time of the larval ecdysis (i.e. complete shedding of the old cuticle) was recorded over 2-h periods as shown on the $x$-axis starting at $6 \mathrm{a} . \mathrm{m}$. The closed and hatched regions on the $x$-axis represent the scotophase and photophase, respectively. Vertical bars represent the percentage that moulted to the fifth instar. Each bar represents the percentage of newly moulted larvae $\pm \mathrm{SE}$ for at least eight determinations. (b) Weights were taken from larvae that initiated head capsule slippage 2 days prior to ecdysis $\left(\mathbf{M}^{-2}\right)$ to the fifth instar (i.e. green-neck), from brown-neck larvae $\left(\mathrm{M}^{-1}\right)$, from newly moulted larvae $(0)$, and from each day of the fifth instar (taken from Thyagaraja et al., 1990b). Each point represents the mean $\pm \mathrm{SE}$ for at least four determinations.

80-90 $\mathrm{ml}$ diet $(N=5-7 / \mathrm{cup})$. The cups were capped with cardboard lids. Faecal matter was removed, and larvae were weighed and observed daily for morphological and behavioural changes associated with the fourth to fifth instar moult (i.e. fourth moult). The larvae were staged during the latter part of the fourth instar according to the moulting characteristics indicated in Table 1.

Larvae completing ecdysis between 3:00 9:00 p.m. of the second day of moulting were held 5-7 per cup, weighed daily, and the growth rate recorded. These were designated Gate II larvae [Fig. 1(a)] and used for all experiments except those reported in Figs 6 and 7(c), where highly synchronized development was less critical. For Gate II larvae, the time at which the old larval cuticle was completely shed was designated day $0(0 \mathrm{~h})$ fifth instar. Gypsy moth larvae reported in Figs 6 and 7(c), that ecdysed during the previous $24 \mathrm{~h}$, were collected and designated day 1 .

\section{Haemolymph ecdysteroid titre determination}

To approximate the time of brain PTTH secretion in fifth-instar larvae, $10 \mu 1$ of haemolymph was col- lected daily in $490 \mu 1$ of ice cold $75 \%$ methanol and also at 4-h intervals from day 4 to day 9 as described by Thyagaraja et al. (1991). Haemolymph was also collected daily from neck-ligated, day 5-7 larvae and day 4-7 starved larvae. Samples (10 12/age group) were collected by piercing the proleg with a fine needle, collecting haemolymph with a glass microlitre pipette and expelling it into methanol, immediately vortexing, placing the samples at $-20^{\circ} \mathrm{C}$ overnight or longer, vortexing again, and centrifuging at $3000 \mathrm{~g}$ for $30 \mathrm{~min}, 4^{\circ} \mathrm{C}$. Aliquots of the supernatant were dried and processed for radioimmunoassay (RIA) by the method of Borst and O'Connor (1972), using $\left[23,24-{ }^{3} \mathrm{H}(N)\right]$ ecdysone $\quad(60-80 \mathrm{Ci} / \mathrm{mmol}), \quad$ NEN Research Products, Boston, MA, U.S.A.) and 20hydroxyecdysone as the competing, non-radioactive ligand. The antibody was a gift from W. E. Bollenbacher, University of North Carolina, Chapel Hill, NC, U.S.A. and its affinity for various ecdysteroids has been characterized (Gilbert et al., 1977). The ratio of the mass of 20-hydroxyecdysone required to displace $50 \%$ of the labelled ecdysone compared to the mass of ecdysone is 2.8 .

\section{Head ligation, decapitation, debraining and starvation}

Fifth-instar larvae were ligated between the head and thorax with a No. 5 braided surgical silk thread (Ethicon Inc., Sommersville, NJ, U.S.A.). Neckligated larvae were immediately decapitated antcrior to the ligation without disrupting the ligation, and the wound was sealed with Bacitracin ointment. Neck ligations were performed on days 4-9 at 4-h intervals to determine the critical period for brain PTTH secretion.

Larval debraining was performed early on day 7 just hefore the head critical period. Larvae were anaesthetized with ether and a small opening made along the triangular markings of the forehead. The brain was removed carefully with fine forceps and the cuticular flap replaced. The wound was smeared with Bacitracin ointment, larvac wcre kept at $15^{\circ} \mathrm{C}$ overnight and then transferred to regular rearing chambers at $25^{\circ} \mathrm{C}$. Sham-operations were conducted using similar procedures except brains were not removed.

To determine effects of starvation on the larvalpupal transformation, larvae were removed from the diet and placed in $125 \times 25 \mathrm{~cm}$ Petri dishes containing wet paper towels. They were starved from days 4-7 of the last instar.

Preparation of extracts and PTTH assay using neckligated larvae

Brains removed from newly ecdysed pupae in Bombyx saline (Okuda et al., 1985) were spread on a 
glass microscope slide with a drop of saline, and areas containing the lateral and median neurosecretory cells carefully dissected. Day-5 larval brains, day-1 pupal brains and day-1 adult brains were also dissected in Bombyx saline. Gypsy moth eggs containing post-diapause embryos just before hatching (Masler et al., 1991) were also collected and extracted. Control tissues such as suboesophageal ganglia, fat body and abdominal foreleg muscle were dissected from day- 5 larvae and pieces the size of a day- 5 brain were used. All tissues were homogenized in Grace's medium in a $1.5 \mathrm{ml}$ polypropylene tube with a tightfitting plastic pestle (Kontes, Vineland, NJ, U.S.A.), placed in boiling water for $2 \mathrm{~min}$, centrifuged at $12,000 \mathrm{~g}$ for $1 \mathrm{~min}$, and the supernatant appropriately diluted in Grace's medium for injection into neck-ligated larvae.

\section{In vivo larval assay}

Day-7 larvae, neck-ligated before the critical period, were held for 5 days (debrained larvae were held for 10 days) to assure that no body shrinkage or internal pupal cuticle formation had occurred. Only ligated and debrained larvae that showed no signs of pharate pupal formation were used for injection. Each ligated larva was injected at the base of the first abdominal proleg with a 27-gauge needle which delivered $10 \mu 1$ of the appropriate dilution. Larvae were scored for body shrinkage and internal pupal cuticle formation 4-5 days after injection. Pupal cuticle formation was observed by carefully removing the old cuticle with forceps. Clear moulting fluid was often extruded except when no pupal cuticle had formed. In that case greenish haemolymph was extruded if the larval cuticle was broken.

\section{In vitro prothoracic gland assay}

Prothoracic glands from day-7 (control) larvae and from treated larvae taken 5 days after neck ligation werc dissected in Bombyx saline. The glands were washed in $100 \mu 1$ of saline for $30-45 \mathrm{~min}$ and right and left glands individually transferred into $25 \mu \mathrm{l}$ drops of Grace's insect culture medium (Gibco, Grand Island, NY, U.S.A.) without insect haemolymph. Incubations were performed in $9 \times 50 \mathrm{~mm}$ covered sterile polypropylene culture dishes in a humidified chamber at $25^{\circ} \mathrm{C}$. Incubation times varied as described below.

(a) Double incubation and gland activation ratio. Using the procedure of Kelly et al. (1992), right and left glands were incubated in separate 25- $\mu 1$ drops of Grace's medium for $2 \mathrm{~h}$, and the incubation medium removed and discarded. The incubation was performed for a second 2 -h period by maintaining the right gland as the control in $25 \mu 1$ of Grace's medium and the left contralateral gland as the experimental preparation in $25 \mu 1$ of brain extract, prepared as described above. Following the 2-h incubation, the incubation medium was analysed by ecdysteroid RIA, using ecdysone as the unlabelled ligand. The ecdysteroid content in the incubation media was expressed as equivalents of the competing, nonradioactive ligand, ecdysone, and represents primarily ecdysone since our antibody is about 100 -fold less sensitive to 3-dehydroecdysone than ecdysone (Kelly et al., 1990b). The gland activation ratio was calculated by dividing the amount of immunodetectable ecdysteroid synthesized by the experimental gland by that of the control gland.

(b) Multiple incubations and net ecdysteroid synthesis. Again using the procedure of Kelly et al. (1992), the prothoracic glands were incubated for $3 \mathrm{~h}$ in $25 \mu \mathrm{l}$ Grace's medium, changing the medium every $60 \mathrm{~min}$. The medium from the last $60 \mathrm{~min}$ was collected for RIA. For the fourth hour, the glands were treated with brain extract, prepared as described above, and the medium again collected for RIA. The net ecdysteroid synthesis was calculated by substracting the amount of ecdysteroid produced during the third $60 \mathrm{~min}$ incubation in Grace's medium from that produced during the fourth with brain extract. To determine the synthesis kinetics, glands were also incubated in $25 \mu$ l Grace's medium for several hours, changing the medium as indicated and analysing aliquots for ecdysteroid by RIA.

\section{RESULTS}

\section{Developmental synchrony during the last-larval instar}

The larvae developed synchronously on high wheat-germ diet. Pharate fourth instars started head capsule slippage 2 days prior to ecdysis to the fifth instar at which time they were separated and observed for their moulting behaviour (Table 1, "Green-neck" stage). Most larvae took at least $27-33 \mathrm{~h}$ to complete the fourth moult. About $30 \%$ of the larvae completed ecdysis early in the morning a few hours after lights on at 5:00 a.m. These were designated as Gate I larvae. About $70 \%$ of the larvae completed ecdysis between 3:00 and 9:00 p.m. These were designated as Gate II larvae [Fig. 1(a)] and were utilized for the present study. Fifth-instar larvae attained a mean maximal weight (over $3 \mathrm{~g}$ ) on day 7 , after which the weight declined [Fig. 1(b)]. Wandering behaviour occurred on day 8 , and nearly $60 \%$ of the larvae pupated on day 11 and the other $40 \%$ on day 12 . 

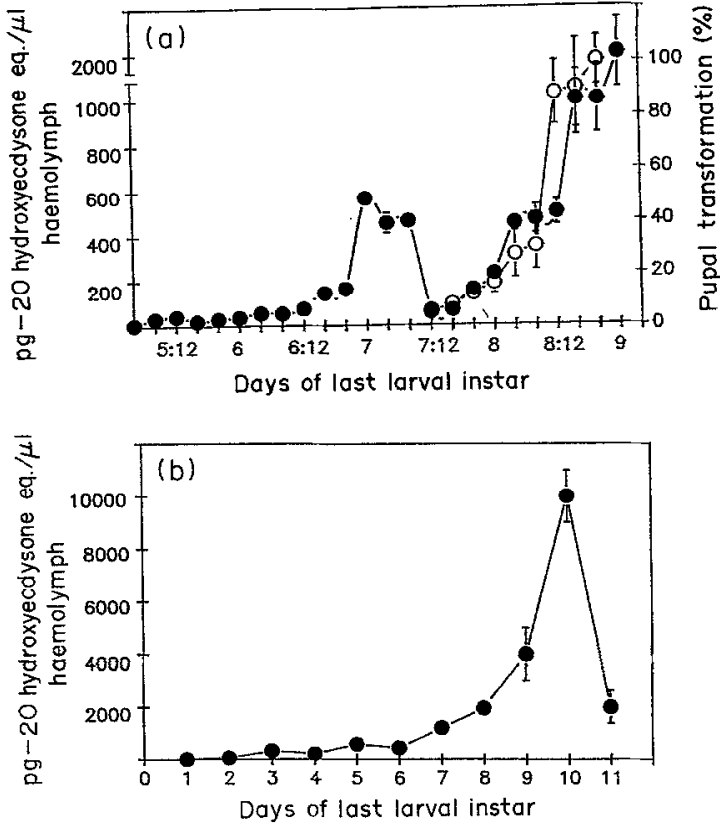

Fig. 2. Haemolymph ecdysteroid titres and pupal transformation in female last-instar larvae. (a) The haemolymph ecdysteroid titre was examined by collecting $10 \mu \mathrm{l}$ of haemolymph, as described in the Materials and Methods, from days 4 to 9 and analysed by RIA (solid circles). Neck ligations were done at 4-h intervals. Neck ligations after day 7 showed various percentages of body shrinkage and pupal transformation (open circles). (b) The haemolymph ecdysteroid titre shown for all 11 days of the last instar. Each point represents the mean $\pm S E$ for at least five determinations.

\section{Larval haemolymph profile and head critical period}

Radioimmunoassay of the haemolymph collected at 4-h intervals during the last-larval instar revealed a small ecdysteroid peak ( $600 \mathrm{pg}$ ) on day 7 [Fig. 2(a)], which lasted for a short period (about $8 \mathrm{~h}$ ) and then dropped to basal levels. The titre began to rise again on day 8 and reached a maximum of nearly 12,000 $\mathrm{pg} / \mu \mathrm{l}$ of haemolymph on day 10 , dropping again to low levels on day 11 [Fig. 2(b)]. Animals neck-ligated after day 7 showed increasing percentages of pupal transformation (Fig. 2).

\section{Larval starvation}

Larvae which were starved during days 4-7 of the last-larval instar showed similar maximal peaks of haemclymph ecdysteroid titre 1 day before pupation [Fig. 3(a)]. Starvation beginning on days 5-7 did not interfere with normal larval development or with the time of pupation. However, there was a weight decrease in the day- 4 , starved larvae which did increase the time to pupation by 1 day but did not interfere with larval-pupal transformation.
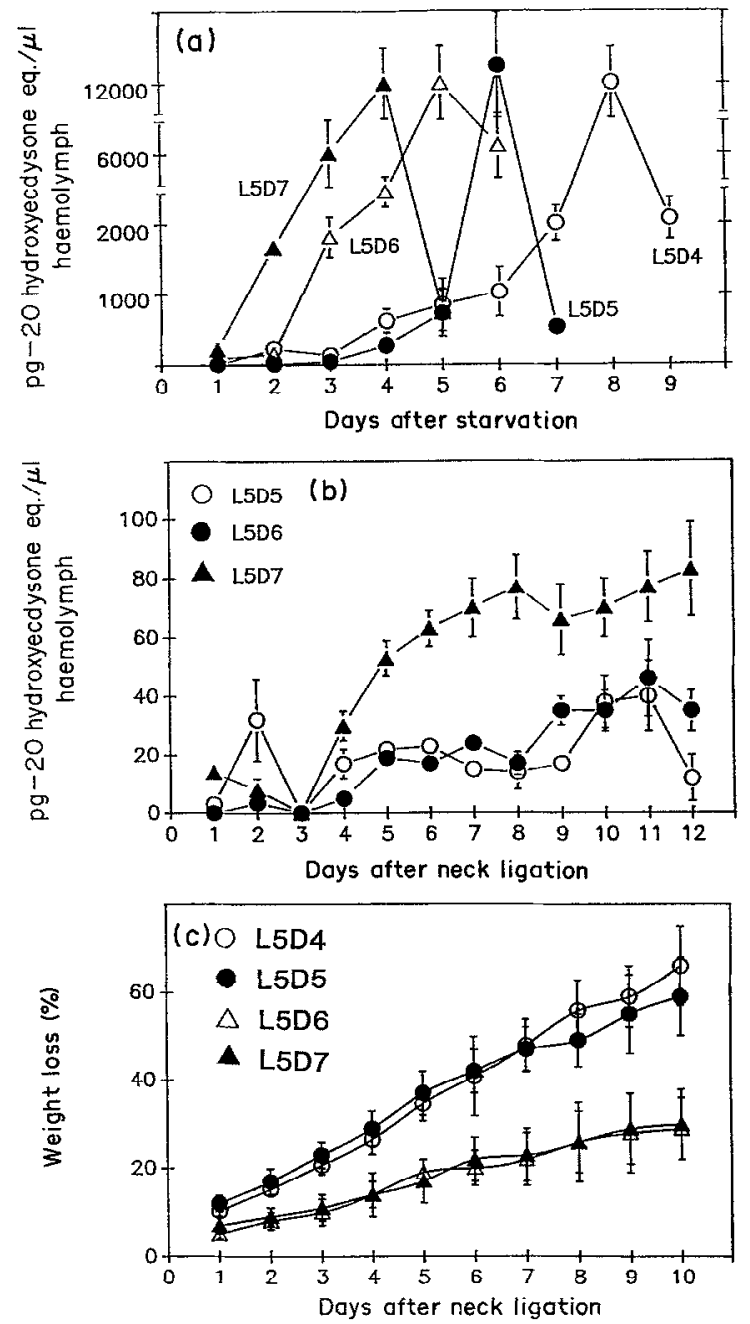

Fig. 3. Haemolymph ecdysteroid titres and percentage weight loss for starved and neck-ligated female larvae. (a) Last-instar gypsy moth larvae were starved beginning on days $4-7$. Ten $\mu 1$ of haemolymph was collected from individual insects on each day of starvation, processed as described in the Materials and Methods, and the supernatant taken for RIA. The designations such as L5D4 represent the day on which starvation was begun and the last point for each starved group represents the day of pupal ecdysis. (b) Haemolymph was collected and processed as described above for neck-ligated, last-instar larvae ligated on days 5,6 or 7 as indicated. (c) Last-instar larvae, days 4-7, were neck-ligated, and larval weights were taken on each day up to 10 days after ligation. The percentage body weight loss was calculated against the average initial weight of the larvae at the time of ligation. Each point is the mean $\pm \mathrm{SE}$ for at least three determinations.

\section{Larval neck-ligation}

Staged larvae which were neck-ligated on days 5, 6 or 7 of the last instar did not initiate pupation even after 20 days, but still remained active. There was a gradual increase in the percentage weight loss to a maximum of $20 \%$ ( 10 days after ligation) in day- 6 and day-7 larvae [Fig. 3(c)]. Day-5, ligated larvae 
showed a rapid loss of body weight and died between days 15-20 [Fig. 3(c)]. These groups showed low titres of haemolymph ecdysteroid [Fig. 3(b)]. The day-5 and day- 6 groups showed a variable ecdysteroid titre of $5-40 \mathrm{pg} / \mu 1$ haemolymph from days 4 to 12 after neck ligation. The titre dropped on day 12 to less than $10 \mathrm{pg} / \mu 1$ in day-5 ligated larvae. The day-7 ligated larvae showed a basal level for 3 days after ligation, started to increase on day 4 and reached a plateau of about $70 \mathrm{pg} / \mu 1$ on day 6 . By day 5 after neck ligation, the haemolymph titre for the day-7, neck-ligated group was significantly higher $(P \leqslant 0.001$; Student's $t$-test) than the titres for day- 5 and day- 6 ligated groups [Fig. 3(b)].

\section{In vitro ecdysteroid secretory ability of the prothoracic glands}

The glands were removed from larvae each day during the last instar and cultured in vitro. Glands from all age groups were able to synthesize ecdysone during the first $90 \mathrm{~min}$ of incubaton, while successive 90-min incubations resulted in a reduction of synthesis. From days 8-10 the glands maintained a high rate [Figs 4(b) and (c)] of synthesis in all successive incubations and reached a maximal rate on day 10 [Fig. 4(d)], the time of peak haemolymph ecdysteroid titre in normal, intact larvae (Fig. 2).

\section{Brain prothoracicotropic hormone (PTTH) profile}

Determination of the brain PTTH activity for each day of the last-larval instar revealed a nearly constant level of PTTH activity for days 4-7 when assayed at 0.04 brain equivalent $/ \mu 1$ Grace's medium [Fig. 5(a)]. The prothoracic glands were activated about 80 -fold with day-1 extract, dropped to 45 -fold with day-3 extract, with maximal activation occurring with day-7 extract, about 90 -fold, and dropping again with day-8 extract. The activity increased again with day- 9 and day-10 extracts, and dropped again with day-11 extract. Activation of the glands with a smaller dose of 0.01 brain equivalents $/ \mu 1$ media revealed peaks of activity on days 3 and 10-11 [Fig. 5(a)]. The in vitro net ecdysteroid synthesis assay of prothoracic glands
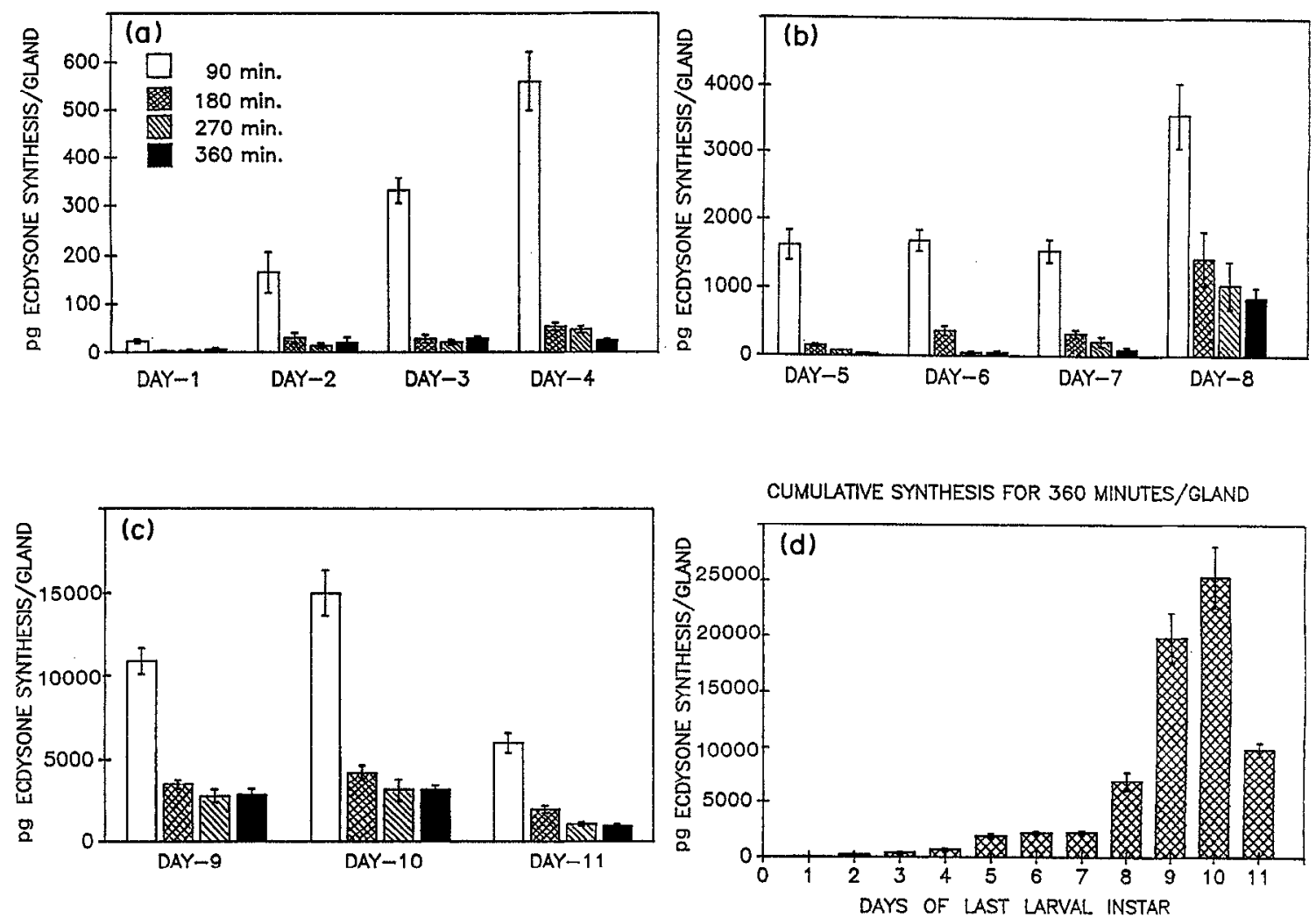

Fig. 4. In vitro ecdysteroid synthetic ability of the prothoracic glands during the last-larval instar. $(a-c)$ Prothoracic glands from days 1 through 11 were incubated for a total of 360 min in $25 \mu$ I drops of Grace's insect culture medium, changed every $90 \mathrm{~min}$. Samples of incubation media were taken from each 90 min change and analysed by RIA. (d) The cumulative synthesis/gland for the total 360 min incubation period. Each bar represents the mean \pm SE for at least three determinations. Note the different $y$-axis range for each plot. 

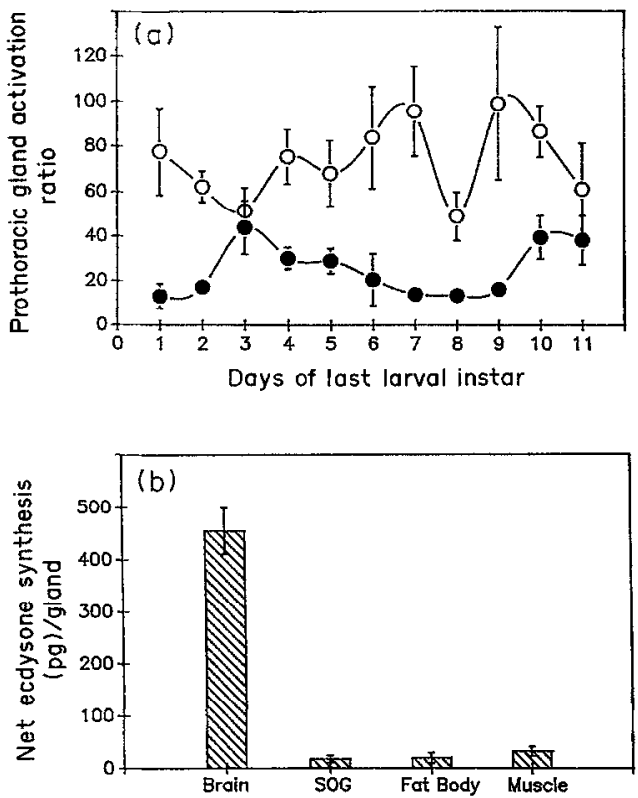

Fig. 5. PTTH activity of various tissues from female lastinstar larvae. (a) Day-4 prothoracic glands were incubated in vitro for $2 \mathrm{~h}$ with $25 \mu \mathrm{l}$ Grace's medium. At $2 \mathrm{~h}$, one gland of a pair received Grace's and the contralateral gland received $25 \mu \mathrm{l}$ boiled brain extract from days 1 to 11 last-instar female larvae at 0.04 equivalent (open circles) and 0.01 equivalent (solid circles) per $\mu 1$ of medium. Glands were incubated for $2 \mathrm{~h}$, and RIAs were done as described in the text. (b) Brain, suboesophageal ganglia (SOG), fat body and muscle from abdominal forelegs were collected from day-5, last-instar female larvae. Extract prepared at 0.04 tissue equivalents $/ \mu 1$ Grace's medium. Net ecdysteroid synthesis assays were conducted as described in the text. Each point is the mean $\pm \mathrm{SE}$ for at least six determinations.

revealed a specificity for brain extract [Fig. 5(b)]. Extracts of suboesophageal ganglia, fat body and leg muscles did not stimulate the glands in vitro [Fig. 5(b)].

\section{Prothoracic glands from neck-ligated larvae}

Prothoracic glands from neck-ligated larvae exhibited ecdysone synthesis during in vitro incubation. The net synthesis assay revealed that the glands from day-7, ligated larvae synthesized more ecdysone than those from day- 6 ligated larvae. Day-7, ligated larvae synthesized a total of more than 2500 pg ecdysone during a 5 -h incubation period, while the day- 6 ligated larvae synthesized a little more than $1200 \mathrm{pg}$ during the same period [Fig. 6(a)]. Furthermore, prothoracic glands from day 7 , neckligated larvae produced more than eight times the amount of ecdysone than those from day-6, ligated animals when exposed to brain extracts in the in vitro net synthesis assay (Table 2). These data suggest that day-7 glands are more mature. Moreover, 5 days after neck ligation they still responded to brain extract in a dose-dependent manner [Fig. 6(b)]. Neck-ligated larval prothoracic glands responded to brain extract
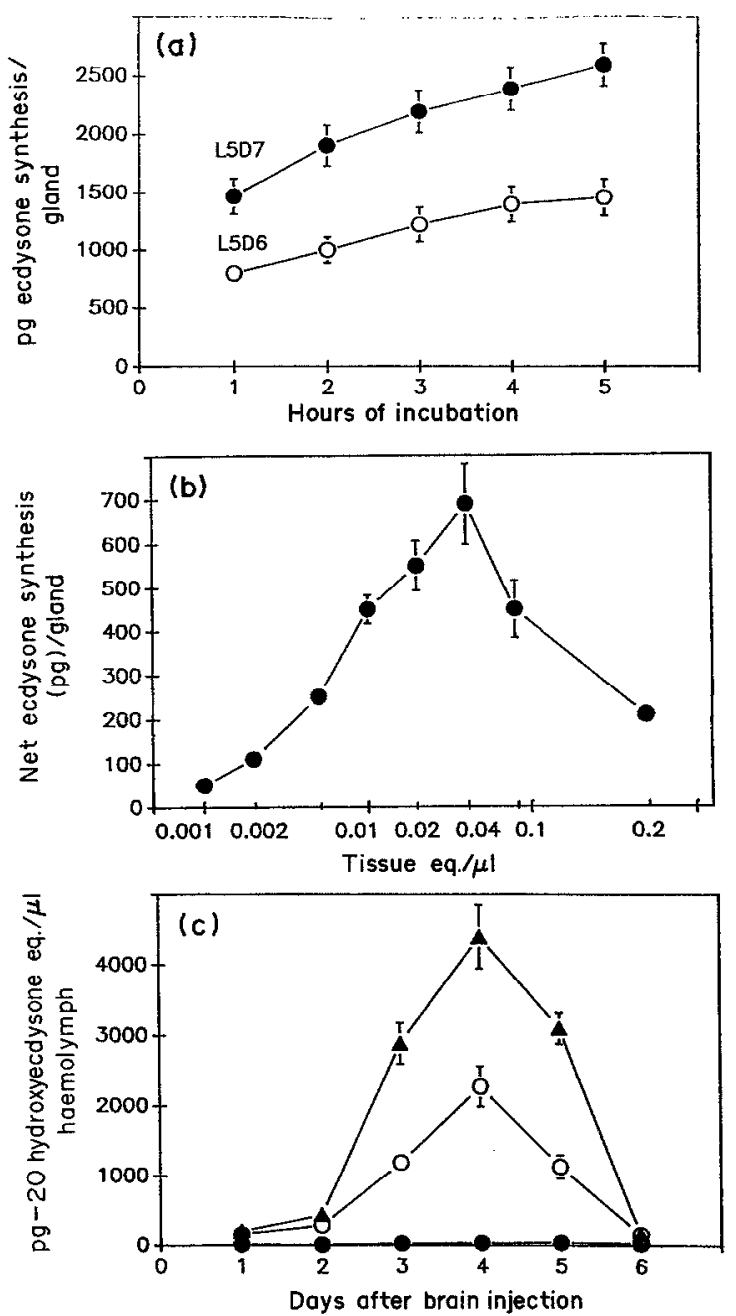

Fig. 6. In vitro and in vivo response of neck-ligated, female last-instar larvae. (a) Prothoracic glands from days 6 and 7, neck-ligated larvae dissected on day 11 were incubated in vitro for $5 \mathrm{~h}$ with $25 \mu \mathrm{l}$ Grace's medium, which was changed every $60 \mathrm{~min}$. Cumulative synthesis is shown for each. (b) Glands were dissected from day-7, neck-ligated larvae 5 days after ligation. Net in vitro prothoracic gland ecdysteroid synthesis with different doses of day-5, larval brain, as described in the text. (c) Day-7, neck-ligated larvae injected with day-5, larval-brain extract at a dose of 0.01 (solid triangles) and 0.04 (open circles) brain equivalents $/ \mu$ l and Grace's medium (solid circles) on day 5 after ligation. Ten $\mu \mathrm{l}$ of haemolymph was collected in $490 \mu 175 \%$ methanol on each day after injection and subjected to RIA. Each point is the mean $\pm S E$ for at least three determinations.

in vitro exhibiting a gradual increase in response at a dose of 0.005 equivalent $/ \mu 1$ and reaching maximal synthesis of nearly $700 \mathrm{pg}$ with 0.04 brain equivalents $/ \mu 1$ media.

In vivo response of neck-ligated larvae to nervous tissue extract

Neck-ligated larvae were injected with brain extract prepared as described in the Materials and 
Table 2. In vitro ecdysone synthesis by prothoracic glands from neck-ligated larvae

\begin{tabular}{|c|c|c|c|c|}
\hline \multirow{3}{*}{$\begin{array}{l}\text { Prothoracic glands } \\
\text { from larvae neck-ligated } \\
\text { on the indicated day* }\end{array}$} & \multicolumn{4}{|c|}{ pg Ecdysone synthesis/gland (hour of incubation) } \\
\hline & First & Second & Third & Fourth $\dagger$ \\
\hline & \multicolumn{3}{|c|}{$25 \mu 1$ Grace's insect medium } & 0.04 Brain Eq. $/ \mu 1$ \\
\hline $\begin{array}{l}\text { L5D4 } \\
\text { (24) }\end{array}$ & $173 \pm 21$ & $94 \pm 13$ & $96 \pm 13$ & $120 \pm 20$ \\
\hline $\begin{array}{l}\text { L5D6 } \\
\text { (29) }\end{array}$ & $740 \perp 55$ & $499 \pm 66$ & $305 \pm 70$ & $530 \pm 68$ \\
\hline $\begin{array}{l}\text { L5D7 } \\
\text { (24) }\end{array}$ & $1483 \pm 144$ & $546 \pm 81$ & $397 \pm 50$ & $2243 \pm 252$ \\
\hline
\end{tabular}

*Glands were dissected on day 11 of the last-larval instar.

†The brains were dissected from day-5, fifth-instar larval donors and used for the in vitro prothoracic gland assay. The numbers in the parentheses denote the number of larvae used for each group. The values are mean \pm SE of at least five determinations.

Methods. Haemolymph was collected each day after injection and ecdysteroid determined by RIA. The 0.01 brain equivalents $/ \mu 1$ Grace's media dose elevated the haemolymph ecdysteroid titre to a maximum of nearly $4500 \mathrm{pg} / \mu 1$ on day 4 after injection, whilc the 0.04 equivalent $/ \mu 1$ dose elevated the haemolymph ecdysteroid titre to only $2000 \mathrm{pg} / \mu 1$ on day 4 [Fig. 6(c)]. All neck-ligated, day-7 larvae injected with brain extract not only showed an elevation of haemolymph ecdysteroid titre [Fig. 6(c)], but also successfully initiated pupation (Fig. 7).

Injection of extract of brain neurosecretory cells along with surrounding brain tissue or injection of extracts of the retrocerebral complex induced pupation in neck-ligated larvae in a dose-dependent manner [Fig. 8(a)]. Lateral neurosecretory cell extract was effective at all doscs, with $40 \%$ pupation occurring at 0.003 tissue equivalents $/ \mu 1$ increasing gradually to a plateau at $0.01-0.04$ equivalent $/ \mu 1$ with nearly $90 \%$ pupation, and dropping again to
$70 \%$ pupation at 0.08 equivalent $/ \mu 1$. Median neurosecretory cell tissue showed the least activity up to 0.02 tissue equivalent $/ \mu 1$, giving responses of 70 and $85 \%$ pupation at higher doses of 0.04 and 0.08 equivalent $/ \mu 1$, respectively. Injections of suboesophageal ganglia, fat body and leg muscle extracts did not induce pupation. Extracts of embryonically mature, post-diapause eggs (i.e. pre-hatch) and brain extract from day-5 larvae, day-1 pupae and day-1 adults also showed induction of pupation in day-7, neck-ligated larvae in a dose-dependent manner [Fig. 8(b)]. However, adult and pupal brains showed a maximal induction of $80-90 \%$ pupation at 0.01 and 0.02 tisuse equivalents $/ \mu 1$, while the day- 5 larval brains induced only $80 \%$ pupation at 0.04 tissue equivalents $/ \mu 1$. Embryonically mature, post-diapause egg extract induced about $80 \%$ pupation at 0.08 tissue equivalents $/ \mu$ l. Similarly, pupation was blocked in debrained animals and could be recovered by injection of brain extract (Table 3).

Table 3. Effect of brain extracts on pupation of debrained larvae

\begin{tabular}{|c|c|c|c|c|c|c|c|c|c|c|c|}
\hline \multirow[b]{2}{*}{ Group } & \multirow{2}{*}{$\begin{array}{c}\text { Number } \\
\text { of } \\
\text { larvae }\end{array}$} & \multicolumn{10}{|c|}{$\begin{array}{l}\text { Number pupating } \\
\text { (days after operation) }\end{array}$} \\
\hline & & 4 & 5 & 6 & 7 & 8 & 14 & 15 & 16 & 17 & 18 \\
\hline Control & 72 & 44 & 26 & 2 & - & - & 一 & - & * & * & * \\
\hline Sham operated & $\begin{array}{l}64 \\
(5)\end{array}$ & - & 32 & 26 & 1 & 一 & - & - & - & * & $*$ \\
\hline Total debrained & $\begin{array}{l}138 \\
(13)\end{array}$ & - & $9 \dagger$ & - & $12 \uparrow$ & $1 \dagger$ & - & - & - & $\dagger$ & $\dagger$ \\
\hline $\begin{array}{l}\text { Debrained + Grace's } \\
\text { Debrained }\end{array}$ & 25 & - & - & - & - & - & - & - & - & - & 一 \\
\hline $\begin{array}{l}+1 \text { brain equivalent } \\
\text { Debrained }\end{array}$ & 26 & - & - & - & - & - & - & - & 16 & 5 & 一 \\
\hline $\begin{array}{l}+0.25 \text { brain equivalent } \\
\text { Debrained }\end{array}$ & 26 & - & - & - & - & - & - & - & 4 & 12 & - \\
\hline+0.0625 brain equivalent & 26 & - & - & - & - & - & - & - & 8 & 4 & $\longrightarrow$ \\
\hline
\end{tabular}

*Control and sham operated groups pupated normally and emerged as adult moths. The number in the parentheses equals post-operational deaths.

†Some debrained larvae showed body shrinkage, intermediate pupal formation and complete pupation. Those forming complete pupae produced normal adults. Some of the remaining animals were used for brain extract injection.

$\ddagger$ Debraining was performed on day-7, fifth-instar larvae as described in the text and the larvae were kept for 10 days and scored for shrinkage and pupation. Active larvae showing no signs of pupation were used for bioassay on the tenth day after debraining. Each was injected with $25 \mu 1$ of brain extract from larvae prepared as described in the text. 

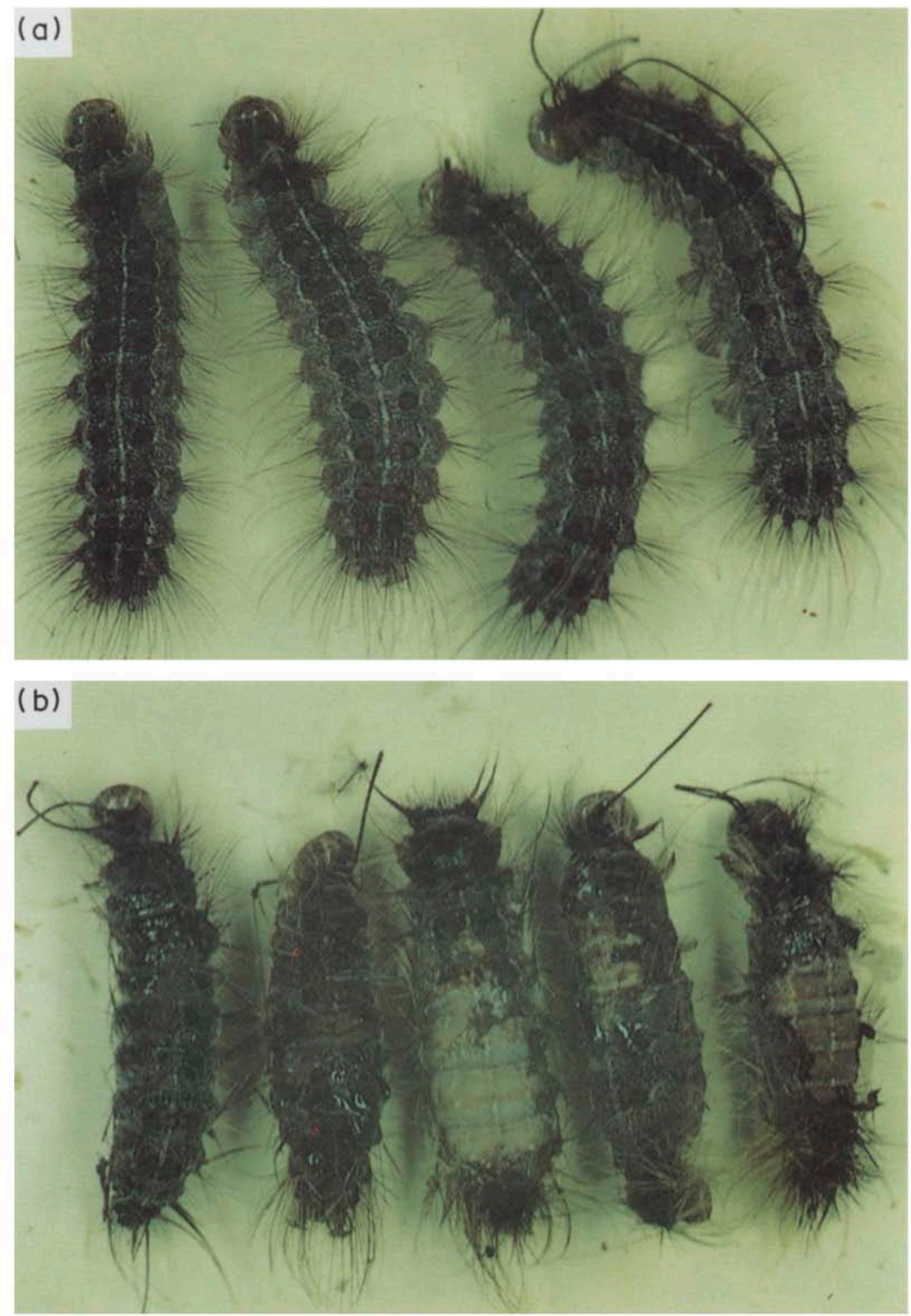

Fig. 7. Response of neck-ligated larvae to injection of exogenous brain hormone. Day-7, neck-ligated larvae were injected with $25 \mu 1$ Grace's medium (a) or brain extract (b) on the fifth day after neck ligation. The brain-extract-injected larvae developed internal pupal cuticle and shrunk. The old-larval cuticle is peeled off to show the formation of internal pupal cuticle. 

The injection of 20-hydroxyecdysone into neckligated larvae also induced pupation in a dosedependent manner. Injection of 0.002 and $0.02 \mu \mathrm{g} / \mu 1$ in $10 \mu 1$ of Grace's medium induced nearly $100 \%$ pupation in neck-ligated larvac [Fig. 8(c)]. Control larvae injected with Grace's medium did not show
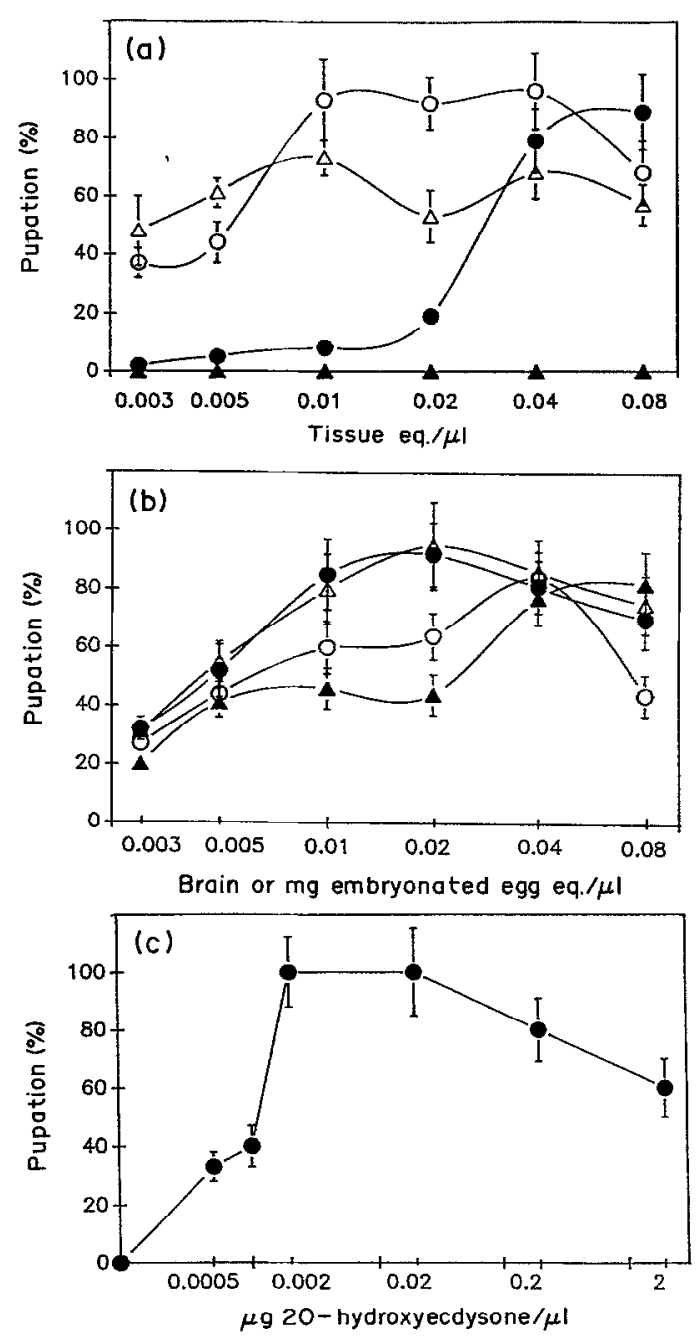

Fig. 8. In vivo effect of injection of neural extracts and 20-hydroxyecdysone on neck-ligated larvae. Day-7 larvae were neck-ligated. On the fifth day the larvae were injected with various tissue extracts or solutions prepared as described in the Materials and Methods. (a) Brain lateral neurosecretory cell tissue (open circles), median neurosecretory cell tissue (solid circles), retrocerebral complexes (open triangles), and suboesophageal ganglia, fat body or abdominal foreleg muscles (solid triangles) from day-5, last-instar larvae. (b) Day-1 adult brain (solid circles), day-1 pupal brain (open triangles), day-5 larval brain (open circles) and embryonically mature gypsy moth eggs (solid triangles). (c) 20-hydroxyecdysone (solid circles). The percentage pupation was scored on days $4-6$ after injection by formation of pupal cuticle inside the outer old-larval cuticle. However, these larvae did not eclose completely. Each point represents the mean $\pm S E$ for at least three determinations. any elevated level of haemolymph ecdysteroid [Fig. 6(c)] nor the induction of pupation.

\section{DISCUSSION}

Insect moulting and metamorphosis depend on the ability of the brain to secrete a hormonal factor inducing these processes (Kopec, 1922; Wigglesworth, 1940; Williams, 1946). The brain hormone, PTTH (Williams, 1947, 1952) stimulates the prothoracic glands in the thoracic region (Hachlow, 1931; Plagge, 1938; Fukuda, 1940a, b) to initiate growth and development by inducing production of a moulting hormone, ecdysone. The timing of PTTH release from the brain and the regulation and action of ecdysteroid for moulting and metamorphosis have been determined using techniques such as neck ligation (Fukuda, 1940a, b; Truman, 1972; Truman and Riddiford, 1974; Fujishita and Ishizaki, 1982; Hiruma and Agui, 1982; Nagata et al., 1987; Tateishi et al., 1989) and through the use of isolated abdomens (Gersch, 1962; Truman, 1972; Kimura, 1974; Truman and Riddiford, 1974; Fujishita and Ishizaki, 1982; Nagata et al., 1987). In Lymantria, development can be blocked successfully by debraining or by isolating the abdomen from the brain through ligation (Kopec, 1917, 1922; Gersch, 1962). The isolated abdomen can be induced to develop by implantation of ring glands from Calliphora accompanied by injection of brain extract from Periplaneta (Gersch, 1962).

In female Lymantria there is a small peak of haemolymph ecdysteroid [Fig. 2(a)] during day 7 of the last-larval instar, that may be important in initiating the cellular and morphological changes necessary for metamorphosis. It is followed by a second larger peak on day 10 , which presumably initiates apolysis. The significance of the first ecdysteroid peak during the final larval instar and its importance for pupal commitment have been described in several lepidopteran insects (see references in Riddiford, 1985; Smith, 1985; Nagata et al., 1987). Studies similar to these will be necessary to determine the significance of this peak in Lymantria. To confirm the necessity of a brain factor for initiation of pupal development of Lymantria, fifth-instar female larvae were neck-ligated every $4 \mathrm{~h}$ from days 4 to 9 . The critical developmental time appeared on days 7-8, after which neck-ligation had no effect on pupation [Fig. 2(a)]. The brain factor, presumably necessary for the stimulation of an early small peak $(600 \mathrm{pg} / \mu 1)$ of ecdysteroid on day-7 [Fig. 2(a)], was blocked through neck ligation on day 7 and resulted in a decrease in titre to about $70 \mathrm{pg} / \mu 1$ up to 12 days after neck ligation [Fig. 3(b)]. Starvation of the larvae after day 4 did not interfere with normal pupation and 
the haemolymph ecdysteroid peaked without delay on day 10 [Fig. 3(a)]. This result suggests that the Lymantria day-4 larval prothoracic gland, which is capable of synthesis of about $600 \mathrm{pg}$ ecdysteroid in the first hour of in vitro incubation [Fig. 4(a)], is competent to respond to internal factors by elevating the haemolymph ecdysteroid titre to a peak of $11,000 \mathrm{pg}$ [Fig. 3(a)], resulting in successful larval-pupal transformation.

Our haemolymph ecdysteroid data on starved larvae [Fig. 3(a)], the in vitro synthesis profile for last-instar larval prothoracic glands from day 1 to day 11 (Fig. 4), and the response to brain extract of glands taken from animals neck-ligated on days 4 to 7 (Table 2) suggest that the larval glands attain an enhanced capacity after day 4 to respond to brain extract. The required period of feeding during the fifth (last)-instar larvae to become competent to initiate pupation is currently being examined and demonstrates a critical period on day 3 , which may involve factors from the head (Thyagaraja et al., unpublished data). The increased synthetic activity of the prothoracic glands during the last-larval instar is well established from day 4 onward [Fig. 4(d)]. The glands attain maximal activity on day 10 .

The PTTH activity for day 1-day 11 larval brains was analysed by the in vitro prothoracic gland assay. Results showed that brains from any day of the last-instar larva are capable of inducing prothoracic gland ecdysteroid synthesis [Fig. 5(a)]. The PTTH activity varies considerably between days 1 and 11 , revealing no significant increase or decrease at any time, when both the 0.04 and 0.01 brain equivalents, $\mu 1$ doses are considered [Fig. 5(a)]. Unlike the brain, the suboesophageal ganglia, fat body and leg muscles did not stimulate ecdysteroid synthesis by the glands in vitro [Fig. 5(b)].

Neck ligation of day-7 larvae before the head critical period effectively caused developmental arrest of up to $95 \%$ without any mortality. Day- 6 and -7 larvae survived for nearly $20-25$ days with a weight loss on only $20 \%$ up to day 10 [Fig. 3(c)]. In contrast, larvae neck-ligated on days 4 and 5 desiccated very fast, resulting in early death. The prothoracic glands were more able to secrete ecdysteroid in vitro in the day-7, ligated group compared to the day-6, ligated group [Fig. 6(a)]. Larval glands from animals neckligated on day-7 also responded to brain tissue extract in a dose-dependent manner [Fig. 6(b)] and day-7, neck-ligated animals responded to brain extract injections in vivo by increasing haemolymph ecdysteroid levels [Fig. 6(c)].

The prothoracic glands from neck-ligated, day- 6 larvae were moderately stimulated with brain extract in vitro, while those from day-7, ligated larvae responded better to brain extract with net synthesis (i.e. fourth-hour synthesis minus third-hour synthesis) nearly 10 times higher (Table 2). Although glands from day-6 ligated larvae were moderately responsive to brain extract in vitro, they never responded in vivo to brain extract, and the injected larvae did not initiate pupation. This suggests that for a normal larval-pupal transformation a minimal threshold dose of haemolymph ecdysteroid [Fig. 3(b)] is necessary and that the prothoracic glands must be competent or mature enough [Figs 6(a), (b) and (c)] to fully interact with the nervous tissue extract. Further confirmation of the necessity of a brain factor for initiation of pupal development was obtained by injecting day-7, neck-ligated larvae with different nervous tissue extracts, 5 days after ligation. Controls, which received Grace's medium, never entered pupation. Extract-injected larvae were scored 5 days later for pupation. All insects injected with brain or retrocerebral complex extracts responded positively and in a dose-dependent manner [Figs 8(a) and (b)]. Similarly, 20-hydroxyecdysone, alone, could elicit pupal ecdysis [Fig. 8(c)].

The present study demonstrates a head critical period for moulting/metamorphosis on day 7 in female, last-instar larvae. Neck ligation or debraining at this time followed by injection of brain extract 5-10 days later subsequently results in pupation within 4-6 days (Table 3 and Fig. 7). Our experiments confirm the existence of PTTH activity in L. dispar, as previously demonstrated by in vitro assay (Kelly et al., 1986, 1992; Masler et al., 1986). Through the development of a Lymantria larval in vivo assay, we have demonstrated the localization of PTTH activity to the lateral and median tissue of the gypsy moth brain and similar PTTH activity in pre-hatch eggs of the gypsy moth (see also Thyagaraja et al., 1990b), confirming similar results with the in vitro prothoracic gland assay (Kelly et al., 1990a, 1991; Masler et al., 1990, 1991; Thyagaraja et al., 1990a). The Lymantria larval in vivo assay has proven to be very sensitive and reliable as shown in our earlier in vivo experiments with Ostrinia nubilalis nervous tissue extracts on ligated $L$. dispar larvae (Gelman et al., 1991, 1992).

Acknowledgements-Belgaum S. Thyagaraja is grateful to the Ministry of Home Affairs (PCR-CELL), Government of India for awarding the National Overseas Scholarship No. BC-11015/5/84-PCR-CELL. Thanks are due to LaVern R. Whisenton and Chih-Ming Yin for helpful comments on manuscript preparation, Carol A. Masler and Carol $\mathrm{H}$. Robinson for technical assistance and Tuananh $T$. $V u$ and Quocanh T. Vu for their help in radioimmunoassay of samples. This work was supported in part by USDA Competitive Grant No. 86-CRCR-1-2111 to E.P.M. and T.J.K. Mention of a commercial or proprietary product in this paper does not constitute endorsement by the USDA. 


\section{REFERENCES}

Bell R. A., Owens C. D., Shapiro M. and Tardif J. R. (1981) Development of mass-rearing technology. In The Gypsy Moth: Research Toward Integrated Pest Management (Eds Doane C. C. and McManus M. L.), USDA Technical Bulletin 1584, pp. 599-655. USDA, Washington, DC.

Bollenbacher W. E. and Granger N. A. (1985) Endocrinology of the prothoracicotropic hormone. In Comprehensive Insect Physiology, Biochemistry and Pharmacology (Eds Kerkut G. A. and Gilbert L. I.), Vol. 7, pp. 109-151. Pergamon Press, Oxford.

Borst D. W. and O'Connor J. D. (1972) Arthropod molting hormone: radioimmune assay. Science 178, 418-419.

Fujishita M. and Ishizaki H. (1982) Temporal organization of endocrinc cvents in relation to the circadian clock during larval-pupal development in Samia cynthia ricini. J. Insect Physiol. 28, 77-84.

Fukuda S. (1940a) Induction of pupation in silkworm by transplanting the prothoracic gland. Proc. imp. Acad. Japan 16, 414-416.

Fukuda S. (1940b) Hormonal control of molting and pupation in the silkworm. Proc. imp. Acad. Japan 16, $417-420$.

Gelman D. B., Thyagaraja B. S., Kelly T. J., Masler E. P., Bell R. A. and Borkovec A. B. (1991) The insect gut: a new source of ecdysiotropic peptides. Experientia 47, $77-80$.

Gelman D. B., Thyagaraja B. S., Kelly T. J., Masler E. P., Bell R. A. and Borkovec A. B. (1992) Prothoracicotropic hormone levels in brains of the European corn borer, Ostrinia nubilalis: diapause vs the non-diapause state. J. Insect Physiol. 38, 383-395.

Gersch M. (1962) The activation hormone of the metamorphosis of insects. Gen. comp. Endocr. 1, 322-329.

Gibbs D. and Riddiford L. M. (1977) Prothoracicotropic hormone in Manduca sexta: localization by a larval assay. J. exp. Biol. 66, 255-266.

Gilbert L. I., Goodman W. and Bollenbacher W. E. (1977) Biochemistry of regulatory lipids and sterols in insects. Int. Rev. Biochem. 14, 1-50.

Hachlow V. (1931) Zur Entwicklungsmechanik der Schmetterlinge. Wilhelm Roux Arch. EntwMech. 125, 26-49.

Hiruma K. and Agui N. (1982) Larval-pupal transformation of the prothoracic glands of Mamestra brassicae. J. Insect Physiol. 28, 89-95.

Ishizaki H., Mizoguchi $\Lambda$., Fujishita M., Suzuki A., Moriya I., O'Oka H., Kataoka H., Isogai A., Nagasawa H., Tamura S. and Suzuki A. (1983a) Species specificity of the insect prothoracicotropic hormone (PTTH): the presence of Bombyx-and Samia-specific PTTHs in the brain of bombyx mori. Devi Growth Diff. 25, 593-600.

Ishizaki H., Suzuki A., Moriya I., Mizoguchi A., Fujishita M., O'Oka H., Kataoka H., Isogai A., Nagasawa H. and Suzuki A. (1983b) Prothoracicotropic hormone bioassay: pupal-adult Bombyx assay. Devl Growth Diff. 25, 585-592.

Kelly T. J. (1992) Fundamental biology of the gypsy moth: a summary of recent research results. In Proc. USDA Interagency Gypsy Moth Research Review 1991 (Eds Gottschalk K. W. and Twery M. J.). USDA Forest Service, Northeastern Forest Experiment Station, Radnor, PA. In press.

Kelly T. J., Masler E. P., Thyagaraja B. S., Bell R. A. and Borkovec A. B. (1986) Prothoracicotropic hormone stimulation of ecdysone synthesis by the prothoracic glands of the gypsy moth, Lymantria dispar. In Insect Neurochemistry and Neurophysiology-1986 (Eds Borkovec A. B. and Gelman D. B.), pp. 327-330. Humana Press, Clifton, NJ.

Kelly T. J., Masler E. P., Thyagaraja B. S., Bell R. A., Gelman D. B., Imberski R. B. and Borkovec A. B. (1990a)
Prothoracicotropic hormone and ecdysteroid ketoreductase from pre-hatch eggs of the gypsy moth, Lymantria dispar. In Insect Neurochemistry and Neurophysiology - 1989 (Eds Borkovec A. B. and Masler E. P.), pp. 357-360. Humana Press, Clifton, NJ.

Kelly T. J., Thyagaraja B. S., Bell R. A., Masler E. P., Gelman D. B. and Borkovec A. B. (1990b) Conversion of 3-dehydroecdysone by a ketoreductase in post-diapause, pre-hatch eggs of the gypsy moth, Lymantria dispar. Archs Insect Biochem. Physiol. 14, 37-46.

Kelly T. J., Masler E. P., Bell R. A., Thyagaraja B. S., Davis R. E., Fescemyer H. W. and Borkovec A. B. (1991) Gypsy moth prothoracicotropic hormones: progress toward identification. In Insect Neuropeptides: Chemistry, Biology and Action (Eds Menn J. J., Kelly T. J. and Masler E. P.), pp. 27-37. ACS Symp. Series 453, Washington, DC.

Kelly T. J., Masler E. P., Thyagaraja B. S., Bell R. A. and Imberski R. B. (1992) Development of an in vitro assay for prothoracicotropic hormone of the gypsy moth, Lymantria dispar (L.) following studies on identification, titers and synthesis of ecdysteroids in last-instar females. J. comp. Physiol. B. In press.

Kimura S. (1974) Relationship between hormone titres and RNA and protein synthesis when the change to the pupal programme occurs in the silkworm, Bombyx mori. J. Insect Physiol. 20, 887-895.

Kobayashi M. (1955) Relationship between the brain hormone and the imaginal differentiation of silkworm, Bombyx mori. J. Sericult. Sci. Jpn 24, 389-392.

Kopec S. (1917) Experiments on metamorphosis of insects. Bull. int. Acat. Sci. Lett. Cracovie (B), pp. 57-60.

Kopec S. (1922) Studies on the necessity of the brain for the inception of insect metamorphosis. Biol. Bull. Mar. Biol. Lab. Woods Hole 42, 322-342.

Mala J., Granger N. A. and Sehnal F. (1977) Control of prothoracic gland activity in larvae of Galleria mellonella. J. Insect Physiol, 23, 309-316.

Masler E. P., Kelly T. J., Thyagaraja B. S., Woods C. W., Bell R. A. and Borkovec A. B. (1986) Discovery and partial characterization of prothoracicotropic hormones of the gypsy moth, Lymantria dispar. In Insect Neurochemistry and Neurophysiology-1986 (Eds Borkovec A. B. and Gelman D. B.), pp. 331-334. Humana Press, Clifton, NJ.

Masler E. P., Kelly T. J., Thyagaraja B. S., Bell R. A., Gelman D. B., Imberski R. B. and Borkovec A. B. (1990) Developmental changes in Lymantria dispar (L.) prothoracicotropic activity from embryo to adult. In Insect Neurochemistry and Neurophysiology-1989 (Eds Borkovec A. B. and Masler E. P.), pp. 353-356. Humana Press, Clifton, NJ.

Masler E. P., Bell R. A., Thyagaraja B. S., Kelly T, J. and Borkovec A. B. (1991) Prothoracicotropic hormone-like activity in the embryonated eggs of gypsy moth, Lymantria dispar (L.). J. comp. Physiol. B 161, 37-41.

Muszynska-Pytel M. (1987) Some aspects of activity regulation of Galleria mellonella PTTH cells. Archs Insect Biochem. Physiol. 5, 211-224.

Nagata H., Ohtaki T. and Sakurai S. (1987) Role of low ecdysteroid titer in acquisition of competence for pupal transformation in Bombyx mori. J. Insect Physiol. 33, $657-662$

Okuda M., Sakurai S. and Ohtaki T. (1985) Activity of the prothoracic gland and its sensitivity to prothoracicotropic hormone in the penultimate and lastlarval instar of Bombyx mori. J. Insect Physiol. 31, 455-461.

Plagge E. (1938) Weitere Untersuchungen über das Verpuppungshormon bei Schmetterlingen. Biol. Ztbl. 58, 1-12.

Riddiford L. M. (1985) Hormone action at the cellular level. In Comprehensive Insect Physiology, Biochemistry 
and Pharmacology (Eds Kerkut G. A. and Gilbert L. I.), Vol. 8, pp. 37-84. Pergamon Press, Oxford.

Smith S. L. (1985) Regulation of ecdysteroid titer: synthesis. In Comprehensive Insect Physiology, Biochemistry and Pharmacology (Eds Kerkut G. A. and Gilbert L. I.), Vol. 7, pp. 295-341. Pergamon Press, Oxford.

Suzuki C. and Ishizaki II. (1986) Prothoracicotropic hormone bioassay: Bombyx larva assay. Int. J. Invert. Reprod. Develop. 10, 259-274.

Tateishi K., Kojima K., Shimizu T., Yagi S and Agui N. (1989) Determination of larval instar number in the common armyworm, Leucania separata (Lepidoptera: Noctuidae) II. Timing of PTTH secretion and ecdysteroid titer for fifth ecdysis. Appl. ent. Zool. 24, 52-58.

Thyagaraja B. S., Kelly T. J., Masler E. P., Bell R. A., Imberski R. B. and Borkovec A. B. (1990a) Developmental profile of prothoracicotropic hormone (PTTH) activity in the gypsy moth, Lymantria dispar. In Insect Neurochemistry and Neurophysiology-1989 (Eds Borkovec A. B. and Masler E. P.), pp. 337-340. Humana Press, Clifton, NJ.

Thyagaraja B. S., Kelly T. J., Masler E. P., Bell R. A., Imberski R. B. and Borkovec A. B. (1990b) Prothoracicotropic hormone (PTTH) regulation of the larval pupal molt in the gypsy moth, Lymantria dispar: observations on the development of a larval in vivo bioassay. In Insect Neurochemistry and Neurophysiology-1989 (Eds Borkovec A. B. and Masler E. P.), pp. 345-348. Humana Press, Clifton, NJ.

Thyagaraja B. S., Kelly T. J., Masler E. P. and Borkovec A. B. (1991) Thyroxine-induced haemolymph protein and cedystcroid incrcases in the silkworm, Bombyx mori: effect on larval growth and silk production. J. Insect Physiol. 37, 153-159.
Truman J. W. (1972) Physiology of insect rhythms I. Circadian organization of the endocrine events underlying the moulting cycle of larval tobacco hornworms. J. exp. Biol. 57, 805-820.

Truman J. W. and Riddiford L. M. (1974) Physiology of insect rhythms III. The temporal organization of the endocrine events underlying pupation of the tobacco hornworm. J. exp. Biol. 60, 371-382.

Twardus D. B. (1991) Spread of the gypsy moth. Gypsy Moth News 25, 1.

Wigglesworth V. B. (1934) The physiology of ecdysis in Rhodnius prolixus (Hemiptera). II. Factor controlling moulting and 'metamorphosis'. $Q$. $J l$ microsc. Sci. 77, 191-222.

Wigglesworth V. B. (1940) The determination of characters at metamorphosis in Rhodnius prolixus (Hemiptera). J. exp. Biol. 17, 201-222.

Wigglesworth V. B. (1985) Historical perspectives. In Comprehensive Physiology, Biochemistry and Pharmacology (Eds Kerkut G. A. and Gilbert L. 1.), Vol. 7, pp. 1-24. Pergamon Press, Oxford.

Williams C. M. (1946) Physiology of insect diapause: the role of the brain in the production and termination of pupal dormancy in the giant silkworm, Platysamia cecropia. Biol. Bull. mar. biol. Lab. Woods Hole 90, 234-243.

Williams C. M. (1947) Physiology of insect diapause. II. Interaction between the pupal brain and prothoracic glands in the metamorphosis of the giant silkworm, Platysamia cecropia. Biol. Bull. Mar. biol. Lab. Woods Hole 93, 89-98.

Williams C. M. (1952) Physiology of insect diapause IV. The brain and prothoracic glands as an endocrine system in the Cecropia silkworm. Biol. Bull. Mar. biol. Lab. Woods Hole 103, 120-138. 